\title{
Cross-cultural adaptation of an innovative approach to learning about difficult conversations in healthcare
}

\author{
GIULIA LAMIANI ${ }^{1}$, ELAINE C. MEYER ${ }^{2,5}$, DANIELA LEONE ${ }^{1}$, ELENA VEGNI ${ }^{1,3}$, DAVID M. BROWNING ${ }^{2,4,5}$, \\ ELIZABETH A. RIDER ${ }^{2,5}$, ROBERT D. TRUOG ${ }^{2,5}$ \& EGIDIO A. MOJA ${ }^{1,3}$ \\ ${ }^{1}$ Universita' degli Studi di Milano, Italy, ${ }^{2}$ Children's Hospital Boston, USA, ${ }^{3}$ San Paolo Hospital, Italy, ${ }^{4}$ Education Development \\ Center, Inc. USA, ${ }^{5}$ Harvard Medical School, USA
}

\begin{abstract}
Background: The Program to Enhance Relational and Communication Skills (PERCS) was developed at a large hospital in the United States to enhance clinicians' preparedness to engage in difficult conversations.

Aim: To describe the implementation of PERCS in an Italian hospital and assess the program's efficacy.

Methods: The Italian PERCS program featured 4-h experiential workshops enrolling 10-15 interdisciplinary participants. The workshops were organized around the enactment and debriefing of realistic case scenarios portrayed by actors and volunteer clinicians. Before and after the workshop, participants rated their perceived preparation, communication and relational skills, confidence, and anxiety on 5-point Likert scales. Open-ended questions explored their reflections on the learning. T-tests and content analysis were used to analyze the quantitative and qualitative data, respectively.

Results: 146 clinicians attended 13 workshops. Participants reported better preparation, confidence, and communication skills $(p<0.001)$ after the workshops. The program had a different impact depending on the discipline. Participants valued the emphasis on group feedback, experiential and interdisciplinary learning, and the patient's perspective, and acquired: new communication skills, self-reflective attitude, reframed perspective, and interdisciplinary teamwork.
\end{abstract}

Conclusion: PERCS proved culturally adaptable to the Italian context and effective in improving participants' sense of preparation, communication skills, and confidence.

\section{Introduction}

Communicating difficult news is a common component of clinical practice in healthcare. For patients and families, how these conversations unfold has a long-lasting impact on their perception of the quality of care, their coping ability, and their bereavement process (Meyer et al. 2002; Mack et al. 2005; Azoulay et al. 2005; Mulry 2007). However, clinicians are poorly prepared to manage this task. It is a common concern among clinicians that communicating difficult news may diminish hope or compound the patient and family's suffering. Clinicians also fear being blamed, not knowing what to say, or unleashing emotional responses they are unprepared to handle (Buckman 1984).

In Italy, the perceived need to protect the patient and the fear of challenging the family's presumed wishes continue to be common challenges of clinical practice (Vincent 1990; Pellegrino 1992; Lamiani et al. 2008). Physicians and healthcare professionals often conceal both diagnosis and prognosis to seriously ill patients in order to maintain their hope (Grassi et al. 2000; Surbone et al. 2004; Surbone 2008). For these reasons, it is not uncommon for clinicians to delay, avoid, or delegate communicating difficult news.

\section{Practice points}

- Implementing the PERCS in Italy has demonstrated that it is possible to culturally adapt learning opportunities that embrace the relational and ethical experience of learners.

- Participants appreciated the innovative pedagogy of the program based on group feedback, experiential and interdisciplinary learning, and the patient's perspective.

- The increased sense of preparation and confidence inspired by PERCS might improve clinicians' willingness to engage more directly in difficult conversations rather than avoiding or delegating them.

- PERCS is a continuing educational offer that hospitals could implement to assist clinicians to reflect on and nurture their professional practice.

In an effort to improve clinicians' preparedness and capability to engage in difficult conversations, in 2002, the Institute for Professionalism \& Ethical Practice at Children's Hospital Boston launched the Program to Enhance Relational and Communication Skills (PERCS) (Browning et al. 2007;

Correspondence: G. Lamiani, Department of Medicine, Surgery and Dentistry, Unit of Clinical Psychology, San Paolo Teaching Hospital, Via Di Rudinì 8, 20142 Milan, Italy. Tel: +39 025032 3129; fax: +39 025032 3015; email: giulia.lamiani@unimi.it 
Meyer et al. 2009). PERCS aims to create an interdisciplinary experiential learning environment in which clinicians can reflect on difficult conversations and the emotional, relational, and ethical implications they entail. After a period of collaboration between the CURA Research Center, University of Milan, and the Institute for Professionalism \& Ethical Practice, Children's Hospital Boston, the PERCS program was culturally adapted to the Italian healthcare context and implemented at San Paolo University Hospital, Milan. The aim of this study was to describe the implementation of the PERCS Program in Italy and to assess the program's effectiveness.

\section{Methods}

\section{Participants}

Participants included physicians, nurses, psychologists, social workers, chaplains, physiotherapists, educators, biologists, and risk managers, who voluntarily enrolled in the Italian PERCS program. Participants were enrolled mainly from San Paolo Hospital, Milan, and other hospitals of the north of Italy. Similar to the American enrollment procedures, participants were recruited through fliers posted on bulletin boards, e-mail invitations sent to unit and service medical directors and nurse managers, and word-of-mouth from participants. Some participants enrolled by checking the website of the program (www.ao-sanpaolo.it/curarsi/psicologia_clinica/).

\section{Intervention}

PERCS is an experiential educational program organized around the enactment and debriefing of realistic case scenarios in a collaborative learning environment (Browning \& Solomon 2006). In a day-long workshop, clinicians have the opportunity to practice difficult conversations with actors, and receive feedback from the actors, interdisciplinary participants, and facilitators. Compared to other communication training programs which use simulated enactments, PERCS is innovative for its pedagogical principles (Browning et al. 2007). During the workshop, participants are encouraged to draw on their pre-existing communicative and relational capacities and to share their opinions especially if different from those of others so as to widen the perspective and contribute to the learning. Debriefings of the simulations are generally responsive to the learners and are driven by participants' questions and insights. In debriefings, medical, relational, ethical, and organizational aspects of care are commonly addressed. Throughout the workshop, facilitators' role consist in creating a nonjudgmental learning environment, promoting equality among learners, challenging common assumptions, honoring multiple perspectives, validating pre-existing competencies, emphasizing moral and relational dimensions of care rather than the acquisition of specific skills, and encouraging self-reflection (Browning et al. 2007).

Given the originality of this educational approach for the Italian healthcare system, the Italian-PERCS was launched in 2008 at San Paolo Hospital, Milan after the first author (GL) apprenticed with the American program in a yearlong Fulbright Scholarship. The implementation of the e58
Italian-PERCS program required an intensive collaboration between the Italian and American centers, entailing bimonthly phone calls between the first author (GL) and the Director of the PERCS program (ECM), five videoconferences between the Italian and American facilitators and actors to discuss progress and challenges in implementing the program, and two crosscultural site visits in Milan and Boston by the Director of the PERCS program (ECM) and by two Italian facilitators (GL and DL).

The Italian-PERCS program offers monthly 4-h workshops enrolling 10-15 interdisciplinary participants and three faculty facilitators, normally a physician or nurse, a psychologist, and an educator. Similar to the American program, the ItalianPERCS commences with an exercise in which participants share communication strategies they had found helpful in their clinical practice, thus recognizing their existing skills. The workshop then continues with the enacted case scenario and debriefings. There are three conversations in the scenario, which are held in a separate room and shown live via video feed to all the participants. In the conversations, actors portray patients and family members and participants volunteer in their roles as clinicians. After each conversation, participants have the opportunity to receive feedback from actors, other participants, and facilitators, reflect on the high points and challenges of the conversations, and review selected segments of the enactment in play back. A more detailed description of the structure of the Italian-PERCS program is published elsewhere (Lamiani et al. 2009).

Compared to the original American PERCS program, the Italian-PERCS had a shortened duration, did not include a family representative in the faculty, and utilized clinical psychologists who had an acting training to portray patients and family members rather than professional actors. Clinical psychologists who had previous experience in acting were selected through an audition held by our actor supervisor. Once selected, the three clinical psychologists received specific training which entailed acting classes, a period of observation in hospital wards, two pilot sessions of acting and debriefing, and attendance to the program development meetings.

To date, three Italian-PERCS programs have been developed, focusing on difficult conversations in adult intensive care (Italian-PERCS-ICU), dialysis (Italian-PERCS-Dialysis), and oncology (Italian-PERCS-Oncology). All these offerings share the same time-frame, pedagogical principles, and educational format, while the specific clinical content and case scenarios differ. The Italian-PERCS case scenarios were built around adult critically ill patients, and reflected communication and ethical challenges appropriate to the Italian practice and legal framework. For instance, the scenario employed in the Italian-PERCS-ICU did not portray an end-oflife decision to withhold or withdraw treatment, as this decision is generally not directly discussed with families, but was focused around the communication of brain death. In the context of the scenario, cultural nuances such as pros and cons of diagnostic concealment, family involvement in decision making, and respect of patient's will were generally discussed as a result of the multiple perspectives expressed by the participants. 


\section{Data collection}

Quantitative and qualitative methods were used to assess the impact of the program. Participants completed confidential pre- and post-questionnaires prior to and immediately following the training. Each participant was assigned a random identification number in order to track their pre- and postquestionnaires. To permit a comparison of the results across countries, we used the same pre- and post-questionnaires used in the evaluation of the American PERCS program (Meyer et al. 2009). Prior to administration, the questionnaires were translated in Italian and back translated into English to insure accuracy by two Italian bilinguals.

On the pre- and post-questionnaires, participants were asked to assess, on 5-point Likert scales, their perceived preparation, communication skills, relational capacities, confidence, and degree of anxiety about having difficult healthcare conversations. The pre-questionnaire also included demographic questions about the participant's discipline, years of experience, previous training, and socio-demographic characteristics. The post-questionnaire asked (in yes/no response format) whether the program had improved the participants' sense of preparation, communication skills, relational capacities, confidence, and/or reduced anxiety about handling difficult conversations. In addition, the post-questionnaire included open-ended questions about most helpful aspects of the program, reflections on the learning, and least helpful aspects as well as suggestions to improve the program.

\section{Data analysis}

Participants' socio-demographic characteristics and responses to yes/no questions were analyzed through descriptive statistics. As the data from the Likert scale items were normally distributed, $t$-tests for paired samples were conducted to examine the difference in participants' self-appraisal of preparation, communication skills, ability to develop and maintain relationships, confidence, and anxiety before and after the training. T-tests were also used to assess participants' selfappraisal of these dimensions by discipline. For this purpose, participants were grouped into: physicians (residents, medical students), nurses, psychosocial professionals (social workers, psychologists), and other (chaplains, physiotherapists, educators, and biologists). Chi square was used to assess differences in the program's ratings of usefulness and quality by discipline. Statistical analyses were completed in SPSS 13 for Windows.

The responses to the open-ended questions were transcribed and qualitatively analyzed through content analysis. Three researchers (GL, DL, EV) independently read the responses to identify themes and issues of importance to participants. Agreement about thematic content and labeling for the themes were then reached through a process of discussion and successive refinement of language. Finally, the frequency of the themes was calculated and excerpts of participants responses were chosen to illustrate each theme.

\section{Research ethics}

The study was reviewed and approved by the Institutional Review Board of San Paolo Hospital, Milan, Italy.
Each participant signed a consent form granting permission for questionnaires to be used for research purpose. The study was supported by the "Centro Universitario di Ricerca sugli Aspetti comunicativo-rleazionali" (C.U.R.A. Research Center) and had no external funding source.

\section{Results}

\section{Quantitative findings}

From July 2008 to January 2010, 13 workshops were offered ( 5 Italian-PERCS-ICU; 5 Italian-PERCS-Dialysis; 3 ItalianPERCS-Oncology) enrolling a total of 146 participants. Of these participants, 129 (88\%) completed both the pre- and the post-questionnaires. Of the 17 missing questionnaires, 14 prequestionnaires were not completed because participants arrived late and 3 post-questionnaires were not completed due to time constraints. Table 1 describes the socio-demographic characteristics of all the participants of the program and of those who returned the questionnaires.

To the yes/no questions, $89 \%$ participants affirmed that the training had improved their preparation, and $86-87 \%$ reported that the training had improved their communication skills, their confidence, and their ability to maintain relationships (Table 2). Fewer participants (60\%) reported that the training had decreased their anxiety in engaging in difficult discussions.

On the Likert scale items, participants reported an improvement in their sense of preparation, communication skills, and confidence (Table 3). No significant differences were found among the results of the three Italian-PERCS programs, across intensive care, dialysis, and oncology. The workshops had a different impact by discipline (Table 4). Nurses and physicians reported improvement in their preparation, confidence, and communication skills, whereas psychosocial professionals improved in preparation and confidence. There were no differences in the program's ratings of quality and usefulness by discipline.

Overall, the Italian-PERCS program was perceived as quite or very useful by $92 \%$ of the participants and the quality of training as good or excellent by $83 \%$ participants. As a testament of the program's usefulness, $96 \%$ of participants reported that they would recommend the training to other colleagues.

\section{Qualitative findings}

Several themes emerged from the open-ended questions focusing on the most useful aspects of the program and reflection on the learning. The themes are reported below along with the number of comments belonging to each theme (in parenthesis). Participants also offered suggestions to improve the program.

\section{Most useful aspects of the program}

\section{Group feedback}

The opportunity to discuss difficult conversations with colleagues in a safe and supportive learning environment was 
Table 1. Socio-demographic characteristics of participants.

\begin{tabular}{|c|c|c|}
\hline Characteristics & $\begin{array}{l}\text { All of the } \\
\text { participants } \\
N=146\end{array}$ & $\begin{array}{c}\text { Participants } \\
\text { who completed } \\
\text { pre- and post- } \\
\text { questionnaires } \\
N=129\end{array}$ \\
\hline \multicolumn{3}{|l|}{ Discipline } \\
\hline Physicians & $46(32 \%)$ & $42(32 \%)$ \\
\hline Nurses & $60(41 \%)$ & 54 (42\%) \\
\hline Psychosocial professionals $^{a}$ & $24(16 \%)$ & $19(15 \%)$ \\
\hline Others ${ }^{b}$ & $16(11 \%)$ & $14(11 \%)$ \\
\hline Valid $N$ & $146(100 \%)$ & $129(100 \%)$ \\
\hline \multicolumn{3}{|l|}{ Years of experience } \\
\hline Mean (SD) & $15.48(9.726)$ & $14.96(9.535)$ \\
\hline Valid $N$ & 132 & 118 \\
\hline \multicolumn{3}{|l|}{ Age } \\
\hline Mean (SD) & $41.87(9.667)$ & $41.31(9.607)$ \\
\hline Valid $N$ & 143 & 129 \\
\hline \multicolumn{3}{|l|}{ Gender } \\
\hline Female & $116(80 \%)$ & $105(81 \%)$ \\
\hline Valid $N$ & 145 (100\%) & $129(100 \%)$ \\
\hline \multicolumn{3}{|l|}{ Ethnicity } \\
\hline Italians & $144(99 \%)$ & $128(99 \%)$ \\
\hline Other & $1(1 \%)$ & $1(1 \%)$ \\
\hline Valid $N$ & 145 (100\%) & $129(100 \%)$ \\
\hline \multicolumn{3}{|c|}{ Previous learning experiences in communication } \\
\hline Coursework & $4(3 \%)$ & $4(4 \%)$ \\
\hline Practicum experience & $36(29 \%)$ & $33(32 \%)$ \\
\hline Residency & $9(7 \%)$ & $8(5 \%)$ \\
\hline Continuing education & $10(8 \%)$ & $10(9 \%)$ \\
\hline Multiple of the above & 49 (40\%) & $44(40 \%)$ \\
\hline Other & $10(8 \%)$ & $11(10 \%)$ \\
\hline Valid $N$ & $122(100 \%)$ & $110(100 \%)$ \\
\hline \multicolumn{3}{|c|}{ Had a role model in communication } \\
\hline Yes & $71(51 \%)$ & $66(52 \%)$ \\
\hline Valid $N$ & $140(100 \%)$ & $128(100 \%)$ \\
\hline \multicolumn{3}{|c|}{ Number of difficult conversations observed } \\
\hline None & $2(2 \%)$ & $2(2 \%)$ \\
\hline $1-10$ & $40(33 \%)$ & $35(31 \%)$ \\
\hline $11-24$ & $11(9 \%)$ & $11(10 \%)$ \\
\hline $25+$ & 67 (56\%) & $63(57 \%)$ \\
\hline Valid $N$ & $120(100 \%)$ & $111(100 \%)$ \\
\hline \multicolumn{3}{|c|}{ Number of difficult conversations led } \\
\hline None & $7(6 \%)$ & $7(7 \%)$ \\
\hline $1-10$ & $32(29 \%)$ & $31(30 \%)$ \\
\hline $11-24$ & $10(9 \%)$ & $10(10 \%)$ \\
\hline $25+$ & $62(56 \%)$ & 55 (53\%) \\
\hline Valid $N$ & $111(100 \%)$ & $103(100 \%)$ \\
\hline
\end{tabular}

Notes: ${ }^{2}$ This category includes psychologists and social workers.

${ }^{\mathrm{b}}$ This category includes chaplains, physiotherapists, educators, biologists, and risk managers.

highly valued. Participants perceived the opportunity of giving and receiving feedback after the conversations as formative ( $n=66)$ : "The possibility of comparison and sharing with the others immediately after the conversation;" "The discussion and the suggestions from the group were very useful," "It was nice to discuss together without feeling judged."

\section{Experiential learning}

Participants appreciated both observing and participating in enacted case scenarios with professional actors $(n=52)$ : "I found it very useful to see a conversation from the outside;" "It was important to 'live' the scenario in first person."

e 60

\section{Table 2. Perceived impact of the program.}

\begin{tabular}{|c|c|c|c|}
\hline Questions & $\begin{array}{l}\text { Yes \% } \\
(n)\end{array}$ & $\begin{array}{l}\text { No } \% \\
(n)\end{array}$ & $\begin{array}{l}\text { Missing } \% \\
(n)\end{array}$ \\
\hline $\begin{array}{l}\text { Has the workshop improved your } \\
\text { sense of preparation to engage } \\
\text { in difficult discussions with } \\
\text { patients and their families? }\end{array}$ & 89 (115) & $9(12)$ & $2(2)$ \\
\hline $\begin{array}{l}\text { Has the workshop improved your } \\
\text { communication skills to engage } \\
\text { in difficult discussions with } \\
\text { patients and their families? }\end{array}$ & $87(112)$ & $11(14)$ & $2(3)$ \\
\hline $\begin{array}{l}\text { Has the workshop improved your } \\
\text { ability to develop and maintain } \\
\text { relationships with patients and } \\
\text { their families? }\end{array}$ & $86(111)$ & 12 (16) & $1(2)$ \\
\hline $\begin{array}{l}\text { Has the workshop improved your } \\
\text { sense of confidence when } \\
\text { engaging in difficult discussions } \\
\text { with patients and their families? }\end{array}$ & 87 (112) & $12(16)$ & $1(2)$ \\
\hline $\begin{array}{l}\text { Has the workshop reduced your } \\
\text { sense of anxiety when engaging } \\
\text { in difficult discussions with } \\
\text { patients and their families? }\end{array}$ & $60(77)$ & $36(46)$ & $5(6)$ \\
\hline $\begin{array}{l}\text { Would you recommend the pro- } \\
\text { gram to others in your position? }\end{array}$ & 96 (124) & $1(1)$ & $3(4)$ \\
\hline
\end{tabular}

\section{Interdisciplinary learning}

The interdisciplinary learning atmosphere, although unfamiliar, was identified by many participants as strength of the program ( $n=27)$ : "It was very useful to discuss with colleagues from different disciplines, and watch different styles of conducting these conversations;" "Sharing thoughts, doubts, and especially listening to different viewpoints;" "The aspect that struck me the most about this program was the usefulness of discussing difficult situations with professionals of different disciplines who end up facing difficult conversations every day in their practice."

\section{The patient's perspective}

The opportunity to gaining understanding about the patient's perspective through the voice of actors and to be able to ask the actors about the impact of communication was perceived as meaningful $(n=20)$ : "I appreciated the possibility of hearing the patient's thoughts without having to ask a real patient;" "To face up to the patient's reality."

\section{Reflections on the learning}

New communication and relational skills. Many participants $(n=72)$ reported the acquisition of new communication and relational skills: "I take home the importance of first listening to all of the problems and needs of the other, and to not make interventions from above;" "Pay more attention to the word choice in critical conversations;" "Leave spaces in the conversation that the patient can fill in... or leave empty."

\section{Reframing of clinician's perspective}

Reflecting on the learning, participants questioned some of their habits and assumptions about clinical practice. 
Table 3. Impact of the program on participants' sense of preparation, communication skills, ability to develop and maintain relationships, confidence, and anxiety.

\begin{tabular}{|c|c|c|c|c|c|}
\hline Dimensions & $\begin{array}{l}\text { Baseline } \\
\text { Mean (SD) }\end{array}$ & $\begin{array}{l}\text { Post-workshop } \\
\text { Mean (SD) }\end{array}$ & $\begin{array}{c}\text { Paired sample } \\
\text { T-Test }\end{array}$ & \multicolumn{2}{|c|}{ 95\% Confidence interval } \\
\hline Preparation $(n=129)$ & $2.84(0.956)$ & $3.33(0.753)$ & $\begin{array}{l}t=-6.681 \\
p<0.001\end{array}$ & -0.633 & -0.344 \\
\hline Communication $(n=129)$ & $3.10(0.856)$ & $3.41(0.777)$ & $\begin{array}{l}t=-5.547 \\
p<0.001\end{array}$ & -0.421 & -0.199 \\
\hline Relationship $(n=129)$ & $3.50(0.651)$ & $3.52(0.708)$ & $\begin{array}{c}t=-0.262 \\
p=0.794\end{array}$ & -0.133 & 0.102 \\
\hline Confidence $(n=129)$ & $2.95(0.883)$ & $3.45(0.696)$ & $\begin{array}{l}t=-7.606 \\
p \leq 0.001\end{array}$ & -0.625 & -0.367 \\
\hline Anxiety $(n=126)$ & $2.83(0.922)$ & $2.67(0.847)$ & $\begin{array}{l}t=1.891 \\
p=0.061\end{array}$ & -0.007 & 0.309 \\
\hline
\end{tabular}

Table 4. Impact of the program on participants' sense of preparation, communication skills, ability to develop and maintain relationships, confidence, and anxiety by discipline.

\begin{tabular}{|c|c|c|c|c|c|c|}
\hline Dimensions & Discipline & $\begin{array}{c}\text { Pre-workshop } \\
\text { Mean (SD) }\end{array}$ & $\begin{array}{c}\text { Post-workshop } \\
\text { Mean (SD) }\end{array}$ & $\begin{array}{c}\text { Paired sample } \\
\text { T-Test }\end{array}$ & \multicolumn{2}{|c|}{ 95\% Confidence interva } \\
\hline \multicolumn{7}{|l|}{ Preparation } \\
\hline & Physicians $(n=42)$ & $3.19(0.943)$ & $3.67(0.612)$ & $\begin{array}{l}t=-4.367 \\
p<0.001\end{array}$ & -0.696 & -0.256 \\
\hline & Nurses $(n=54)$ & $2.76(0.845)$ & $3.26(0.705)$ & $\begin{array}{l}t=-3.881 \\
p<0.001\end{array}$ & -0.758 & -0.242 \\
\hline & Psychosocial professionals $(n=19)$ & $2.89(0.994)$ & $3.47(0.772)$ & $\begin{array}{l}t=-3.644 \\
p=0.002\end{array}$ & -0.913 & -0.245 \\
\hline & Others $(n=14)$ & $2.07(0.917)$ & $2.43(0.514)$ & $\begin{array}{c}t=-1.439 \\
p=0.174\end{array}$ & -0.893 & 0.179 \\
\hline \multicolumn{7}{|c|}{ Communication } \\
\hline & Physicians ( $n=42$ ) & $3.48(0.773)$ & $3.74(0.627)$ & $\begin{array}{c}t=-2.707 \\
p=0.010\end{array}$ & -0.457 & -0.067 \\
\hline & Nurses $(n=54)$ & $2.94(0.811)$ & $3.33(0.752)$ & $\begin{array}{l}t=-4.016 \\
p<0.001\end{array}$ & -0.583 & -0.195 \\
\hline & Psychosocial professionals $(n=19)$ & $3.26(0.806)$ & $3.47(0.697)$ & $\begin{array}{l}t=1.714 \\
p=0.104\end{array}$ & -0.469 & 0.047 \\
\hline & Others $(n=14)$ & $2.36(0.745)$ & $2.64(0.842)$ & $\begin{array}{c}t=-2.280 \\
p=0.040\end{array}$ & -0.556 & 0.015 \\
\hline \multicolumn{7}{|l|}{ Relationship } \\
\hline & Physicians $(n=42)$ & $3.76(0.617)$ & $3.88(0.550)$ & $\begin{array}{l}t=-1.403 \\
p=0.168\end{array}$ & -0.290 & 0.052 \\
\hline & Nurses $(n=54)$ & $3.39(0.627)$ & $3.39(0.627)$ & $\begin{array}{l}t=0.000 \\
p=1.000\end{array}$ & -0.205 & 0.205 \\
\hline & Psychosocial professionals $(n=19)$ & $3.53(0.612)$ & $3.58(0.769)$ & $\begin{array}{l}t=-0.438 \\
p=0.667\end{array}$ & -0.305 & 0.200 \\
\hline & Others $(n=14)$ & $3.14(0.663)$ & $2.86(0.770)$ & $\begin{array}{l}t=1.295 \\
p=0.218\end{array}$ & -0.191 & 0.762 \\
\hline \multicolumn{7}{|l|}{ Confidence } \\
\hline & Physicians $(n=42)$ & $3.36(0.850)$ & $3.71(0.636)$ & $\begin{array}{l}t=-3.048 \\
p=0.004\end{array}$ & -0.594 & -0.121 \\
\hline & Nurses $(n=54)$ & $2.85(0.763)$ & $3.44(0.604)$ & $\begin{array}{l}t=-6.336 \\
p<0.001\end{array}$ & -0.780 & -0.405 \\
\hline & Psychosocial professionals $(n=19)$ & $2.74(0.933)$ & $3.37(0.684)$ & $\begin{array}{l}t=-3.076 \\
p=0.007\end{array}$ & -1.063 & -0.200 \\
\hline & Others $(n=14)$ & $2.43(0.938)$ & $2.79(0.802)$ & $\begin{array}{c}t=-2.110 \\
p=0.055\end{array}$ & -0.723 & 0.009 \\
\hline \multicolumn{7}{|l|}{ Anxiety ${ }^{a}$} \\
\hline & Physicians $(n=41)$ & $2.68(0.789)$ & $2.51(0.675)$ & $\begin{array}{l}t=1.361 \\
p=0.181\end{array}$ & -0.083 & 0.424 \\
\hline & Nurses $(n=52)$ & $2.73(0.888)$ & $2.63(0.841)$ & $\begin{array}{l}t=0.697 \\
p=0.489\end{array}$ & -0.181 & 0.373 \\
\hline & Psychosocial professionals $(n=19)$ & $3.05(0.911)$ & $2.79(0.976)$ & $\begin{array}{l}t=1.229 \\
p=0.235\end{array}$ & -0.187 & 0.713 \\
\hline & Others $(n=14)$ & $2.29(1.267)$ & $3.14(1.027)$ & $\begin{array}{l}t=0.694 \\
p=0.500\end{array}$ & -0.302 & 0.588 \\
\hline
\end{tabular}

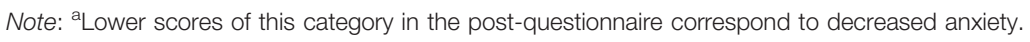


Clinicians commented on the importance of authenticity, humanity, hope, and respect for the patient's autonomy in difficult conversations $(n=32)$ : "Coming to the training $I$ expected to get techniques and guidelines to follow in order to not make mistakes. What I have learned is that I am allowed to make mistakes, it is human. The most important thing is how to recover from mistakes;" "Offer information with a clear, honest communication, without false hopes;" "I take bome the possibility of letting the patients choose what they want to know;" "I learned the importance of silence and respect of the person's will;" "Never forget the buman part of our job."

\section{Self-reflective attitude}

Clinicians reported they had acquired a self-reflective attitude and renewed commitment to their work $(n=32)$ : "I take homel greater awareness about others' pain;" "How many things there are in a conversation that we do not realize!;" "Useful spur to self-critique;" "I found it useful to reflect about how having knowledge and a script, can sometimes be helpful, but other times can be blinding;" "Everyday I ask myself for how long I can keep on with this work because it is hard and burdensome work, and I say to myself: "I do not know, I will see, tomorrow I will think about it." Today on the contrary I don't say "tomorrow I will think about it." I do say that I still enjoy it, I love this job, I will go on."

\section{Interdisciplinary teamwork}

Learning in an interdisciplinary setting allowed participants to appreciate the contribution of the other healthcare professionals to these conversations and to strengthen their commitment to interdisciplinary teamwork $(n=10)$ : "From now on I would like to involve the nurse during the patient's visit;" "Team-work is necessary to manage difficult conversations;" "I understood the importance of collaboration and synergy between all of the healthcare professionals."

\section{Suggestions for the program}

Participants recommended that the training be spread as much as possible and that it be repeated more often $(n=15)$ : "This training should be mandatory for all who work in the bealthcare setting." Participants also expressed $(n=4)$ the need to tailor the PERCS model to new clinical challenges (e.g., conflict management, managing he aggressive patients). Critical comments about the program were: the amount of time dedicated to the theoretical presentation $(n=14)$ ("The power point presentation was the least useful aspect"), the specificity of the program content $(n=6)$ ("Broaden the issues;" "The program is too focused on dialyzed patients"), the duration of the training $(n=5)$ ("Too short of a time"). Methodological considerations $(n=23)$ were also offered as points of discussion ("I am not sure that having mixed professional roles could always be useful;" "Offer more clinical cases so that other professionals and not only physicians and nurses can participate;" "Do not use only actors to simulate patients but also participants.")

e62

\section{Discussion}

In Italy, Continuing Medical Education devoted to communication training programs for practicing clinicians is generally discipline-specific, focused on the acquisition of concrete skills, and offered as a one-time educational activity (Vegni et al. 2002; Vegni \& Moja 2004; Costantini et al. 2009). Although many of these trainings are taught by psychologists, the attendance is very poor and response by clinicians less than enthusiastic. PERCS is innovative in the Italian healthcare setting because it is an interdisciplinary continuing educational offering that combines the learning of communication skills with reflection on the emotional and ethical aspects of care (Zoppi \& Epstein 2002; Branch et al. 2009). The program proved to be logistically adaptable to the Italian healthcare context and was judged to be relevant to everyday clinical practice and worthwhile to attend. The high number of participants, their positive responses, and the presence of a waiting list, suggest that this type of relational learning is appreciated and needed in other healthcare settings beyond the United States.

Overall, the Italian-PERCS program was effective in improving participants' sense of preparation, communication skills, and confidence in holding difficult conversations. Our results are remarkably consistent with the American study (Meyer et al. 2009), which reported that the training was most effective in improving participants' preparation, communication skills, and confidence, thus suggesting the cross-cultural veracity and utility of the educational paradigm. In the openended questions, participants reported learning communication skills, such as initiating conversations by inquiring about the patient's concerns, recognizing the value of silence, approaching the conversations gradually and with humanity, confronting one's own emotions, and strengthening one's commitment to interdisciplinary teamwork. These areas of competence, emphasized in many of the approaches for breaking bad news (Buckman 1992; Rabow \& McPhee 1999; Baile et al. 2000; Back et al. 2009) are also associated with increased patient and family satisfaction and less conflict with healthcare staff (Bertakis et al. 1991; McDonagh et al. 2004). Many clinicians recognized that they had relational abilities that were relevant and trustworthy, but that had never before been professionally validated or encouraged by the medical culture. The validation of pre-existing relational abilities, combined with the discovery of new communication skills, was described by participants as empowering. Since selfperception of competence is a useful predictor of taskavoidance or commitment behavior (De Beni 2000), it is possible that the increased sense of preparation and confidence inspired by PERCS might improve clinicians' willingness to engage more directly in difficult conversations rather than avoiding or delegating them.

The program did not significantly increase clinicians' selfappraisal of their ability to develop relationships or lower their anxiety when having difficult conversations. As in the American study, participants were least likely to report an increase in their ability to establish and maintain relationships. Participants' baseline level of establishing relationship with patients was the highest self-appraisal, therefore leaving less 
room for improvement in this dimension. It is also possible that this broadly defined dimension (establishing relationships) might need a more specific or nuanced definition and means of measurement in order to be accurately assessed. Regarding clinicians' anxiety, consistent with the American data, some participants reported no change or even greater anxiety after the workshop. The literature highlights that communicating difficult news is normally accompanied by feelings of anxiety (Panagopoulou et al. 2008). A certain level of anxiety can be adaptive in stressful situations and may reflect an enhanced appreciation of the complexity and gravity of these conversations. The stability and even the worsening of the level of anxiety and of the ability in establishing relationships reported by some participants may reflect an over-appraisal of these competencies prior to the workshop and a correction of selfappraisal as a consequence of the training.

Unlike the American program, the Italian-PERCS program had a differential impact depending on professional discipline. Nurses and physicians benefited the most from the training, increasing in preparation, communication skills and confidence, areas in which there is a lack of formal training. Psychosocial professionals did not report an increase in communication or relational skills, probably because these competencies are already well-integrated into their professional training. However, as a result of the program, psychosocial professionals improved in preparation and confidence to hold difficult healthcare conversations. Interestingly, physicians were the professionals whose baseline self-appraisal was the highest across all of the dimensions. This finding invites reflection about how physicians go about managing selfimage, especially when they are often the main bearers of bad news. Non-judgmental, collaborative learning in an interdisciplinary context, using simulation and video review, can be a useful source of feedback and appropriate calibration of selfappraisal for physician learners (Fryer-Edwards et al. 2006; Calhoun et al. 2009).

Despite the different impact of the training on discipline, there were no differences by discipline in the ratings of the program's quality and usefulness. From participants' comments, we learned that one of the most useful features of the program was the opportunity to observe and appreciate the contribution that colleagues from other disciplines can offer in these conversations. Although single-discipline trainings have shown favorable outcomes (Back et al. 2003; Lorin et al. 2006; Rimondini et al. 2009), in the highly hierarchical Italian healthcare setting, interdisciplinary learning has the potential to enhance interdisciplinary teamwork and bring about organizational change with attendant improvements in clinical practice and enhanced care coordination.

The study design has several limitations. Our evaluation did not include a control group and participants were self-selected, which may have diminished the generalizability of the findings. Evaluation of the program was based exclusively on self-reported measures, and thus was subject to the limitations associated with self-reported measures. The impact of the program on participants' clinical interactions with patients and families remains to be investigated.

As the value of communication is increasingly recognized and even mandated as part of professional training, effective and logistically feasible programs will be needed (Rao et al. 2007). The flexibility and efficacy of the PERCS educational approach has led to its expanded application, in our hospital and across Italy, to a range of other difficult conversations, such as disclosure of medical error, communication of the informed consent, and student-patient communication. Our findings suggest that the PERCS program holds promise as a culturally adaptable, innovative pedagogical approach to learning about the art of difficult conversations in healthcare.

\section{Acknowledgments}

The authors thank Raffaella Balestrieri, Sonja Gerosa, Marco Lunardelli, Emanuela Mauri, Giovanni Mistraletti for their contributions to the program, Egidio Corizzo and Allyson Wall for their technical support, Serena Barello and Daniela Ometti for the data entry, and Antonella Gullotta, Ivan Fossati, and Alessandro Gabetta for making the conversations real. A special thanks to all the participants to the PERCS program. The program was funded by the CURA Research Center and San Paolo Hospital, Milan.

Declaration of interest: The authors report no declarations of interest. The authors alone are responsible for the content and writing of this article.

\section{Notes on contributors}

GIULIA LAMIANI, MS, EdM, is a Research Fellow at the CURA Research Center, Università degli Studi di Milano.

ELAINE C. MEYER, PhD, RN, is the Director of the Program to Enhance Relational and Communication Skills, Director of the Institute for Professionalism and Ethical Practice, and an Associate Professor of Psychology in the Department of Psychiatry at Harvard Medical School.

DANIELA LEONE, MS, is a Psychologist at San Paolo Hospital, Milan, and Research Fellow at the CURA Research Center, Università degli Studi di Milano.

ELENA VEGNI, MS, is an Associate Professor of Clinical Psychology in the Department of Medicine, Surgery and Dentistry at Università degli Studi di Milano.

DAVID M. BROWNING, MSW, BCD is a Senior Scholar at the Institute for Professionalism and Ethical Practice and a Lecturer at Harvard Medical School.

ELIZABETH A. RIDER, MSW, MD is the Director of Academic Programs, Institute for Professionalism and Ethical Practice, and an Assistant Professor of Pediatrics, Harvard Medical School.

ROBERT D. TRUOG, MD, is a Professor of Medical Ethics, Anesthesia, and Pediatrics at Harvard Medical School, and Executive Director of the Institute for Professionalism and Ethical Practice.

EGIDIO A. MOJA, MD, is a Professor of Clinical Psychology in the Department of Medicine, Surgery and Dentistry at Università degli Studi di Milano, and Director of the CURA Research Center.

\section{References}

Azoulay É, Pochard F, Kentish-Barnes N, Chevret S, Aboab J, Adrie C, Annane D, Bleichner G, Bollaert PE, Darmon M, et al. 2005. Risk of post-traumatic stress symptoms in family members of intensive care unit patients. Am J Respir Crit Care Med 171:987-994.

Back A, Arnold R, Tulsky J. 2009. Mastering communication with seriously ill patients. 1st ed. New York: Cambridge University Press. 
Back AL, Arnold RM, Tulsky JA, Baile WF, Fryer-Edwards KA. 2003. Teaching communication skills to medical oncology fellows. J Clin Oncol 21:2433-2436.

Baile W, Buckman R, Lenzi R, Glober G, Beale EA, Kudelka AP. 2000 SPIKES-A six-step protocol for delivering bad news: Application to the patient with cancer. Oncologist 5:302-311.

Bertakis KD, Roter D, Putnam SM. 1991. The relationship of physician medical interview style to patient satisfaction. J Fam Pract 32:175-181.

Branch WT, Frankel R, Gracey CF, Haidet PM, Weissmann PF, Cantey P, Mitchell GA, Inui TS. 2009. A good clinician and a caring person: Longitudinal faculty development and the enhancement of the human dimensions of care. Acad Med 84:117-125.

Browning DM, Meyer EC, Truog RD, Solomon MZ. 2007. Difficult conversations in health care: Cultivating relational learning to address the hidden curriculum. Acad Med 82:905-913.

Browning DM, Solomon MZ. 2006. Relational learning in pediatric palliative care: Transformative education and the culture of medicine. Child Adolesc Psychiatr Clin N Am 15:795-815.

Buckman R. 1984. Breaking bad news. Why is still so difficult? BMJ 288(6430):1597-1599.

Buckman R. 1992. How to break bad news: A guide for health care professionals. Toronto: University of Toronto Press.

Calhoun A, Rider EA, Meyer EC, Lamiani G, Truog RD. 2009. Assessment of communication skills and self-appraisal in the simulated environment: Feasibility of multirater feedback with gap analysis. Simul Healthc 4:22-29.

Costantini A, Baile WF, Lenzi R, Costantini M, Ziparo V, Marchetti P, Grassi L. 2009. Overcoming cultural barriers to giving bad news: Feasibility of training to promote truth-telling to cancer patients. J Cancer Educ 24:180-185.

De Beni R, Moè A. 2000. Motivation and learning. Bologna Il Mulino, Italian.

Fallowfield L, Jenkins V. 2004. Communicating sad and difficult news in medicine. Lancet 363:312-319.

Fryer-Edwards K, Arnold RM, Baile W, Tulsky JA, Petracca F, Back A. 2006. Reflective teaching practices: An approach to teaching communication skills in a small group setting. Acad Med 81:638-644.

Grassi L, Girali T, Messina EG, Magnani K, Valle E, Cartei G. 2000 Physicians' attitudes to and problems with truth-telling to cancer patients. Support Care Cancer 8:40-45.

Lamiani G, Meyer EC, Browning DM, Moja EA. 2009. Between science and suffering: Difficult conversations in healthcare. Recenti Prog Med 100:239-246, Italian.

Lamiani G, Meyer EC, Rider EA, Browning DM, Vegni E, Mauri E, Moja EA, Truog RD. 2008. Assumptions and blind spots in patient-centredness: Action research between American and Italian healthcare professionals. Med Educ 42:712-720.
Lorin S, Rho L, Wisnivesky JP, Nierman DM. 2006. Improving medical student Intensive Care Unit communication skills: A novel educational initiative using standardized family members. Crit Care Med 34:2386-2391.

Mack JW, Hilden JM, Watterson J, Moore C, Turner B, Grier HE, Weeks JC, Wolfe J. 2005. Parent and physician perspectives on quality care at the end of life in children with cancer. J Clin Oncol 23:9155-9161.

McDonagh JR, Elliott TB, Engelberg RA, Treece PD, Shannon SE, Rubenfeld GD, Patrick DL, Curtis JR. 2004. Family satisfaction with family conferences about end-of-life care in the intensive care unit: Increased proportion of family speech is associated with increased satisfaction. Crit Care Med 32:1484-1488.

Meyer EC, Burns JP, Griffith JL, Truog RD. 2002. Parental perspectives on end-of-life care in the pediatric intensive care unit. Crit Care Med 30:226-231.

Meyer EC, Sellers DE, Browning DM, McGuffie K, Solomon MZ, Troug RD. 2009. Difficult conversations: Improving communication skills and relational abilities in healthcare. Pediatr Crit Care Med 10:352-359.

Mulry C. 2007. I have an update ... . Patient Educ Couns 65:3-4.

Panagopoulou E, Mintziori G, Montgomery A, Kapoukranidou D. 2008. Concealment of information in clinical practice: Is lying less stressful than telling the truth? J Clin Oncol 26:1175-1177.

Pellegrino E. 1992. Is true telling to the patient a cultural artifact? JAMA 268:1734-1735.

Rabow MW, McPhee SJ. 1999. Beyond breaking bad news: How to help patients who suffer. West J Med 171:260-263.

Rao JK, Anderson LA, Inui TS, Frankel RM. 2007. Communication interventions make a difference in conversations between physicians and patients. Med Care 45:340-334.

Rimondini M, Del Piccolo L, Goss C, Mazzi M, Paccaloni M, Zimmermann C. 2009. The evaluation of training in patient-centred interviewing skills for psychiatric residents. Psychol Med 23:1-10.

Surbone A, Ritossa C, Spagnolo AG. 2004. Evolution of truth-telling attitudes and practices in Italy. Crit Rev Oncol Hematol 52:165-172.

Surbone A. 2008. Information to cancer patients: Ready for new challenges? Support Care Cancer 16:865-868.

Vegni E, Martinoli M, Moja EA. 2002. Improving patient-centred medicine: A preliminary experience for teaching communication skills to Italian general practitioners. Educ Health 15:51-57.

Vegni E, Moja EA. 2004. Effects of a course on ophthalmologist communication skills: A pilot study. Educ Health 17:163-171.

Vincent JL. 1990. European attitudes towards ethical problems in intensive care medicine: Results of an ethical questionnaire. Intensive Care Med 16:256-264

Zoppi K, Epstein RM. 2002. Is communication a skill? Communication behaviors and being in relation. Fam Med 34:319-324. 